\title{
A Novel MAP Kinase Gene in Cotton (Gossypium hirsutum L.), GhMAPK, is Involved in Response to Diverse Environmental Stresses
}

\author{
Meimei Wang, Ying Zhang, Jian Wang, Xiaoliang Wu and Xingqi Guo* \\ Shandong Key Laboratory of Crop Biology, College of Life Sciences, Shandong Agricultural University, Taian, Shandong, 271018, China
}

Received 22 September 2006, Accepted 7 December 2006

The mitogen-activated protein kinase (MAPK) cascade is one of the major and evolutionally conserved signaling pathways and plays pivotal role in the regulation of stress and developmental signals in plants. Here, a novel gene, termed Gossypium hirsutum MAPK (GhMAPK), was isolated from cotton. The full-length cDNA of GhMAPK encodes for a 372 amino acid protein that contains all 11 of the MAPK conserved subdomains and the phosphorylationactivation motif, TEY. Amino acid sequence alignment revealed that GhMAPK shared high identity with group-C MAPK in plants and showed $83 \sim 89 \%$ similarities with MAPKs from Arabidopsis, apricot, pea, petunia, and tobacco. Southern blot analysis indicated that the GhMAPK belonged to a multygene family in cotton. Two introns were found within the region of genomic sequence. Northern blot analysis revealed that the transcripts of GhMAPK accumulated markedly when the cotton seedlings were subjected to various abiotic stimuli such as wounding, cold $\left(4^{\circ} \mathrm{C}\right)$, or salinity stress; Furthermore, $G h M A P K$ was upregulated by the exogenous signaling molecules, such as salicylic acid (SA) and hydrogen peroxide $\left(\mathrm{H}_{2} \mathrm{O}_{2}\right)$, as well as pathogen attacks. These results indicate that the GhMAPK, which has a high degree of identity with group-C plant MAPKs, may also play an important role in response to environmental stresses.

Keywords: Cotton, Environmental stresses, Mitogenactivated protein kinases, Molecular cloning, RACE

\section{Introduction}

Plants are often subjected to stresses during their growth and defense genes have been involved in the stress release

\footnotetext{
* To whom correspondence should be addressed.

Tel: 86-538-8245679; Fax: 86-538-8226399

E-mail: xqguo@sdau.edu.cn
}

process. Protein phosphorylation/dephosphorylation is a key regulatory mechanism in modulating the activation of these defense genes (Trewavas and Gilroy, 1991; Stone and Walker, 1995). The mitogen-activated protein kinase (MAPK) cascades are known to be one of the major phosphorylation pathways which function downstream of sensors/receptors and regulate cellular responses to external and endogenous stimuli (Hirt, 1997). A typical MAPK cascade consists of three steps: a MAP kinase kinase kinase (MAPKKK) activates a particular MAP kinase kinase (MAPKK) through phosphorylation on two serine/threonine residues in a conserved S/T-X3-5-S/T motif, the activated MAPK can in turn phosphorylates a MAPK on threonine and tyrosine residues in the invariant sequence TXY (Cobb and Goldsmith, 1995; Jonak et al., 2002; Nakagami et al., 2005).

To date, more than 60 MAPKs have been isolated and characterized in plants, and the analysis of Arabidopsis genome sequences has revealed the existence of more than 20 $M A P K$ genes (Asai et al., 2002), which suggests that the MAPK cascades in plant may be quite complex. Based on the phylogenetic analysis of amino acid sequence and phosphorylation motif, plant MAPKs can be grouped into at least four groups (A, B, C, and D) (Jonak et al., 1999; MAPK Group, 2002). Among them, MAPKs in groups A and B are mostly involved in signaling of biotic and abiotic stress such as cold, drought, wounding, pathogen attack (Jonak et al., 1996; Agarawal et al., 2002; Xiong and Yang, 2003; Jonak et al., 2004) and hormones (Zhang and Klessig, 1998; Seo et al., 1999; Ouaked et al., 2003). Limited data are available on group-C MAPKs, and it seems that some of them are involved in cell cycle regulation (Baögre, et al., 1999) and some involved in environmental stress responses (Tu et al., 2002). All Group-D MAPKs have the TDY motif instead of TEY motif which is conserved in the subgroup A, B and $\mathrm{C}$. Besides, they have a long C-terminal extension domain (Tanouet et al., 2000). It have been reported that two members of this group, $O s B W M K 1$ and $M s T D Y 1$, can be activated by pathogen attack and mechanical wounding (He et al., 1999; Cheong et al., 2003; Champion et al., 2005). 
Above facts suggest that MAPKs play crucial roles in plant growth and development. In order to obtain more information on the specific structural and regulatory patterns of MAPKs, it is necessary to isolate and characterize more $M A P K$ genes from different species. The molecular and biochemical characterization of $M A P K$ genes in plant has been studied extensively, but, most of those studies are carried out in model plant species such as Arobidopsis, tobacco and rice. Cotton (Gossypium hirsutum) is an economically important species, its MAPKs, however, have not been reported before. This is the first study on the existence of a MAPK cascade component in cotton and its possible involvement in several stress responses. The isolation, characterization and expression of a $M A P K$ gene from cotton were also as a part of a further study on enhancing the resistance of cotton to fungal diseases.

\section{Materials and methods}

Plant materials and treatments. Cotton seed (Gossypium hirsutum L. cv lumian 22) was first surface sterilized (70\% aqueous ethanol for $5 \mathrm{~min}$, then rinsed in sterile water), then incubated in petri dishes between sheets of moist filter paper for $48 \mathrm{~h}$ at $28^{\circ} \mathrm{C}$. Germinated seedlings were transferred to tissue culture pots (sterile water) and incubated for a further 5 days at $28^{\circ} \mathrm{C}$ under a $16 \mathrm{~h} \mathrm{light/}$ $8 \mathrm{~h}$ dark cycle. The 7-day-old plants were subjected respectively to different treatments. The edges of cotton leaves were cut with scissors for wounding treatment. Cold treatment was performed by placing the seedlings in a $4^{\circ} \mathrm{C}$ growth room. SA and $\mathrm{H}_{2} \mathrm{O}_{2}$ treatment were performed by spraying $10 \mathrm{mM} \mathrm{SA}$ and $10 \mathrm{mM} \mathrm{H}_{2} \mathrm{O}_{2}$ onto cotton seedling leaves respectively. Salt stress was imposed on the seedlings by placing the roots in $200 \mathrm{mM} \mathrm{NaCl}$ solution. For susceptible plant-pathogen interaction, seedlings were removed from the pots and inoculated by root dip into a conidial suspension of Fusarium oxysporum f. sp. Vasinfectum (Dowd et al., 2004).
Primers. The primers used in this study are presented in Table 1.

RNA preparation, cDNA synthesis and DNA extraction. Leaf was harvested after each treatment and all samples were frozen in liquid nitrogen and stored at $-80^{\circ} \mathrm{C}$ for analysis. Total RNA was extracted with the RNeasy plant mini kit (Qiagen) according to the manufacture's protocol. Total RNA extracted from leaves after 30 min of wounding stress treatment was treated with DNAase I (Promega) in order to remove potential genomic DNA contamination. First-strand cDNA was then synthesized from $2 \mu \mathrm{g}$ of total RNA by M-MLV reverse transcriptase (TaKaRa) and an adaptor primer B26 at $42^{\circ} \mathrm{C}$ for $60 \mathrm{~min}$.

Genomic DNA was isolated from seedling leaves using a modified hexadecyltrimethylammonium bromide (CTAB) method (Jeong et al., 2006). The quality and concentration of RNA and DNA samples were examined by ethidium bromide-stained agarose gel electrophoresis and spectrophotometer analysis.

Cloning of the middle region of GhMAPK. To get the internal conservative fragment, primers MP1 and MP2 (Table 1) were designed and synthesized based on the conserved amino acid and nucleotide sequences of plant MAPK genes (Shanghai Sangon Biotechnological Company, China). Reverse transcription-PCR (RT-PCR) was programmed as below: pre-denatured at $94^{\circ} \mathrm{C}$ for 5 min, followed by 35 cycles of amplification $\left(94^{\circ} \mathrm{C}\right.$ for $1 \mathrm{~min}, 50^{\circ} \mathrm{C}$ for $1 \mathrm{~min}, 72^{\circ} \mathrm{C}$ for $1 \mathrm{~min}$ ), and then followed by extension for 5 min at $72^{\circ} \mathrm{C}$. The PCR product was purified using Gel Extraction Kit (TaKaRa), ligated to pMD18-T vector (TaKaRa), transformed into $E$. coli strain $\mathrm{DH} 5 \alpha$, and then sequenced.

3' RACE. Based on the sequence of the cloned internal fragment, two gene specific primers $3 \mathrm{P} 1$ and $3 \mathrm{P} 2$ were designed and synthesized. The first round of PCR was performed with 3P1 and universal primer B26. The PCR product was diluted 100-fold for a second round of amplification with $3 \mathrm{P} 2$ and nested universal primer B25. The reactions were performed as follows: $94^{\circ} \mathrm{C}$ for $5 \mathrm{~min} ; 35$

Table 1. The primers used in this study

\begin{tabular}{lll}
\hline Abbreviation & \multicolumn{1}{c}{ Sequence $\left(5^{\prime}-3^{\prime}\right)$} & \multicolumn{1}{c}{ Description } \\
\hline MP1 & GGHGCHTAYGGVATHGTNTG & degenerate primer, Forward \\
MP2 & GTNACNACRTAYTCNGTCAT $(\mathrm{H}=\mathrm{A}, \mathrm{C}$, or T; $\mathrm{N}=\mathrm{A}$, & degenerate primer, Reverse \\
3P1 & C, G, or T; $\mathrm{R}=\mathrm{A}$ or $\mathrm{G} ; \mathrm{V}=\mathrm{A}, \mathrm{C}$, or $\mathrm{G} ; \mathrm{Y}=\mathrm{C}$ or T) & Forward primer for 3 RACE, outer \\
3P2 & GACTTTGGACTGGCACGCAC & Forward primer for 3 RACE, nested \\
B26 & CACGCACTAGCAATGCCAAG & 3-RACE adapter primer \\
B25 & GACTCGAGTCGACATCGAT $(\mathrm{T})_{18}$ & 3-RACE universal primer \\
5P1 & GACTCGAGTCGACATCGAT & Reverse primer for 5 RACE, outer \\
5P2 & TCTCCTATGAGTCGGCATC & Reverse primer for 5 RACE, nested \\
AAP & TTCACGCAAAGTTCTGAGAG & Abridged Anchor Primer \\
AUAP & GGCCACGCGTCGACTAGTAC $(\mathrm{G})_{14}$ & Abridged universal amplification primer \\
HP1 & GGCCACGCGTCGACTAGTAC & Gene specific primer, Forward \\
HP2 & CAGGAAAATGGCAACTCCAG & Gene specific primer, Reverse \\
GP1 & CAGTGGTAAGACAACATCGT & Gene specific primer, Forward \\
GP2 & GCTTGATACTTTACGGCGTCG & Gene specific primer, Reverse \\
RtP2 & TAACAGGAGTTGCGAAGACAT & Gene specific primer, Reverse \\
\hline
\end{tabular}


cycles of amplification $\left(94^{\circ} \mathrm{C}\right.$ for $1 \mathrm{~min}, 59^{\circ} \mathrm{C}$ for $1 \mathrm{~min}, 72^{\circ} \mathrm{C}$ for $1 \mathrm{~min}$ ); $72^{\circ} \mathrm{C}$ for $5 \mathrm{~min}$. The amplified product was purified and cloned into pMD18-T vector followed by sequencing.

5' RACE. To obtain the 5'-ready cDNA, the first-strand cDNA was purified using the DNA Clean-up System (Promega, USA) according to the manufacturer's instructions, and then polyadenylated at its 5'end with dGTP by terminal deoxynucleotidyl transferase (TaKaRa, Japan); this was followed by ethanol precipitation and resuspended in distilled deionized water. Primers 5P1 and 5P2 were designed based on the sequence of the cloned internal fragment. The first round of PCR was performed with Abridged Anchor Primer (AAP) and 5P1, the PCR product was diluted 100-fold for nested PCR with a second round of amplification with Abridged Universal Amplification Primer (AUAP) and 5P2. The two steps were carried out under the following conditions: $94^{\circ} \mathrm{C}$ for $5 \mathrm{~min}$; 35 cycles of amplification $\left(94^{\circ} \mathrm{C}\right.$ for $1 \mathrm{~min}, 52^{\circ} \mathrm{C}$ for $1 \mathrm{~min}, 72^{\circ} \mathrm{C}$ for $\left.1 \mathrm{~min}\right)$; extended at $72^{\circ} \mathrm{C}$ for $5 \mathrm{~min}$. The amplified fragment was electrophoresed, gel extracted and cloned into the cloning vector pMD18-T and sequenced.

The full-length cDNA and genomic sequence amplification of GhMAPK. By aligning the sequences of 3' RACE, 5' RACE and the middle region products, the full-length cDNA sequence of GhMAPK was deduced and then amplified using gene-specific primers HP1 and HP2. After sequenced, the full-length cDNA of $G h M A P K$ was subsequently analyzed for molecular characterization. Two gene-specific primers, GP1 and GP2, designed based on the cDNA sequence was used to amplify the genomic sequence of GhMAPK.

Southern blotting analysis. Genomic DNA (30 $\mu \mathrm{g} / \mathrm{sample})$ was digested for $24 \mathrm{~h}$ at $37^{\circ} \mathrm{C}$ with EcoRI and Hind III respectively, fractionated by $1.0 \%$ agarose gel electrophoresis and transferred onto a Hybond- $\mathrm{N}^{+}$Nylon membrane (Amersham Pharmacia, England) using a method described by Sambrook et al. (1989). The partial coding sequence at 3'-end divergent region of GhMAPK ( $\approx 500$ bp) was generated by PCR using primers $3 \mathrm{P} 1$ and rtP2 and was labeled with $\left[\alpha-{ }^{32} \mathrm{P}\right] \mathrm{dCTP}$ according to the manufacturer's instruction of Primer-a-Gene ${ }^{\circledR}$ Labeling System (Promega, USA), then used as the probe in Southern blotting analysis. The hybridization was carried out for $24 \mathrm{~h}$ at $65^{\circ} \mathrm{C}$. After hybridization, the blots were washed four times with $2 \times \mathrm{SSC}, 0.1 \% \mathrm{SDS}$ and $0.2 \times \mathrm{SSC}, 0.1 \%$ SDS for $10 \mathrm{~min}$ each at $42^{\circ} \mathrm{C}$, and then exposed to an X-ray film (Kodak, Japan) using two intensifying screens for $5 \mathrm{~d}$ at $-80^{\circ} \mathrm{C}$.

Northern blotting analysis. $30 \mu \mathrm{g}$ of total RNA was separated by denaturing $1.0 \%$ agarose gel, stained with ethidium bromide to ensure equal loading; and then transferred to Hybond- $\mathrm{N}^{+}$Nylon membranes. Full-length cDNA of GhMAPK was used as probe in the Northern blotting analysis. The hybridization conditions were same with that in Southern blotting. All Southern and Northern analysis experiments were repeated at least twice using independent samples and representative results are presented.

\section{Results}

Cloning and sequence analysis of the full length cDNA of GhMAPK. Based on the conserved region of plant MAPK genes, primers MP1 and MP2 were designed and synthesized for the amplification of the middle region of GhMAPK. A fragment of about $500 \mathrm{bp}$ showing high homology to $P h M E K 1$ (X83440) was obtained. Two forward specific primers 3P1 and $3 \mathrm{P} 2$ designed according to the obtained internal region were used for the amplification of 3'-end cDNA of GhMAPK, resulting in a single and specific fragment of about $900 \mathrm{bp}$. After 5' RACE, a fragment of about $750 \mathrm{bp}$ was obtained with two reverse specific primers 5P1 and 5P2 designed based on middle region. After analysis of the two corresponding fragments, which overlapped each other in, the full-length cDNA sequence of GhMAPK was deduced. Whole coding sequence of GhMAPK about 1200 bp was obtained after RTPCR with specific primers HP1 and HP2, which was identical to the deduced cDNA. Thus, we got the full-length cDNA sequence of GhMAPK.

The full-length cDNA of GhMAPK (GeneBank accession number DQ132852) was 1832 bp long with a 5' untranslated region (UTR) of $341 \mathrm{bp}$ and a 3' UTR of $542 \mathrm{bp}$. The cDNA contained a 1119-bp open reading frame (ORF) encoding a protein of 372 amino acids with a calculated molecular weight of about $45.9 \mathrm{kDa}$ and an isoelectric point of 7.37.

Sequence analysis of GhMAPK at protein level. The predicted amino acid sequence of GhMAPK was aligned with other known MAPKs from various plants using DNAman software as shown in Fig. 1. The GhMAPK protein contained all 11 subdomains that are conserved among all MAPK families (Hirt, 1997). The TEY motif, which includes the threonine and tyrosine residues whose phosphorylation is necessary for MAP kinase activation and is a feature of MAPK, is also conserved between subdomains VII and VIII. Construction of a dendrogram based on the homologous fulllength amino acid sequences suggests that GhMAPK can be grouped into group C (Fig. 2). GhMAPK has high homologues with NtNTF3 (89.54\%) from Nicotiana tobaccum, PsMAPK2 (87.13\%) from Pisum sativum, PhMEK1 (85.68\%) from Petunia x hybrida, PaMAPK (84.72\%) from Prunus armeniaca, AtMPK1 (83.91\%) from Arabidopsis thaliana, which are all members of group $\mathrm{C}$.

Genomic structure analysis of GhMAPK. Southern blotting was performed to obtain a rough estimation of copy number of GhMAPK in cotton genome. Genomic DNA was completely digested with EcoRI and Hind III respectively, and hybridized to 3 '-end partial coding sequence generated by RT-PCR, which have no internal restriction site from EcoRI and Hind III. Detection of one major band along with at least four weakly 


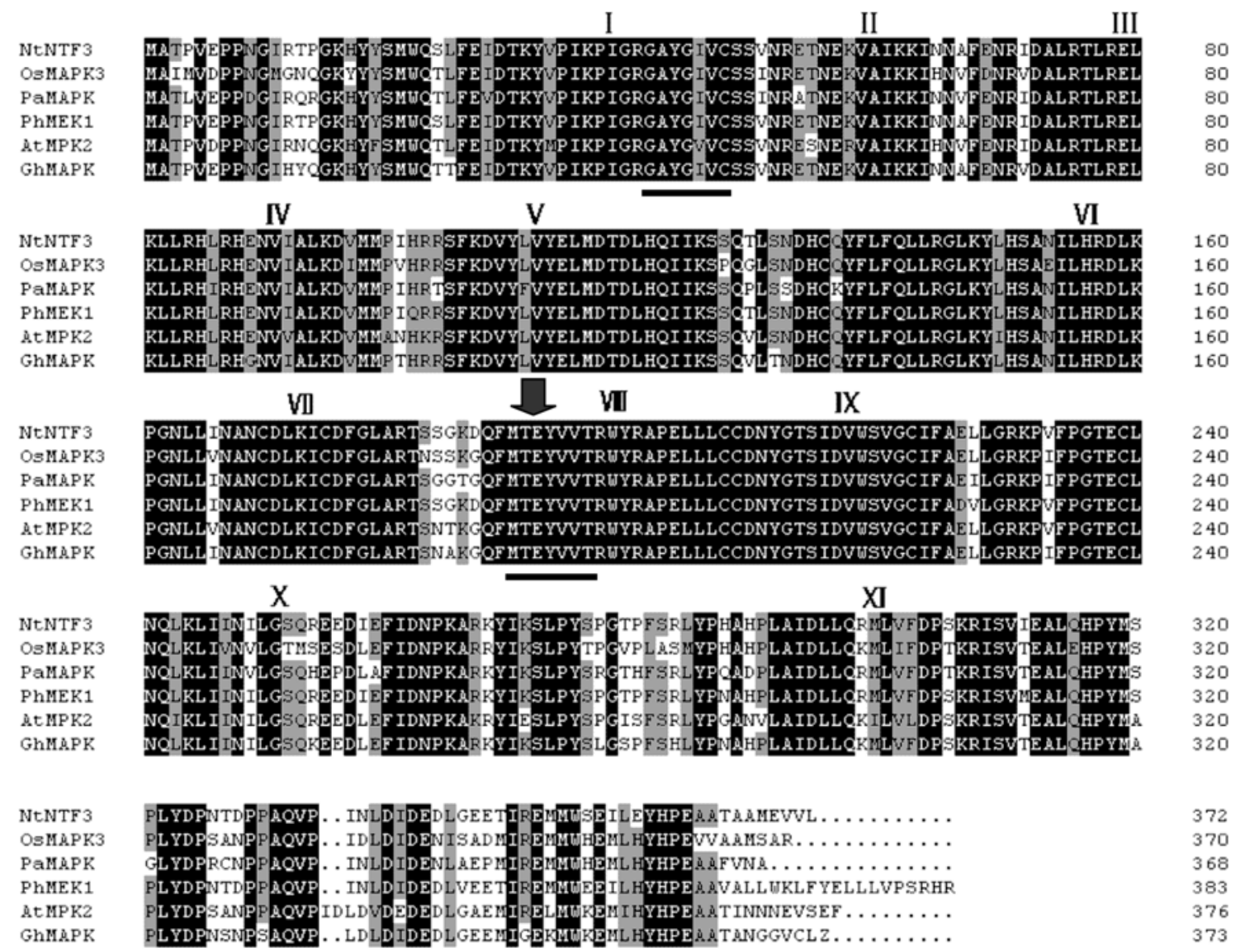

Fig. 1. Alignment of the deduced GhMAPK protein sequence (DQ132852) with MAPKs from other members of group-C MAPKs: NtNTF3 (X69971), OsMAPK3 (AF216317), PaMAPK (AF134730), PhMEK1 (X83440), AtMPK2 (D14714). Identical and similar amino acid residues in this alignment were shaded in black and gray, respectively. The 11 MAP kinase subdomains are labelled by roman numerals. The conserved motif TEY was indicated by arrowhead. The positions of the degenerate primers MP1 and MP2 was underlined.

hybridizing bands suggests the presence of other $M A P K$ genes that share some homology with $G h M A P K$, and there might be a $M A P K$ gene family in cotton genome (Fig. 3).

In order to isolate a genomic GhMAPK clone, a pair of primers, GP1 and GP2, was designed based on the sequence of the $5^{\prime}$ and $3^{\prime}$-UTR of the cDNA and was used in PCR with genomic cotton DNA as template. After reaction, we got a 2603-bp gene fragment encompassing 1490-bp cDNA sequence and found that it was interrupted by 1113-bp introns. Comparison between the GhMAPK genomic and cDNA sequence indicated that two introns ( $248 \mathrm{bp}$ and $865 \mathrm{bp}$ each) were present in the gene. The intron insertion positions were showed in Fig. 4. Both introns showed a high AT content (71\% for intron $1,66 \%$ for intron 2 ) and splice site consensus 5'-GT and AG-3' which are typical structural characteristics of plant introns.

Changes in mRNA level of GhMAPK in response to abiotic stresses (wounding, low temperature and salt stress). Evidence has shown that MAPK cascade is involved in several signal transduction pathways in plant; thus, we first examined the effects of some abiotic stresses on the expression of $G h M A P K$ in seedling leaves. After cutting leaves, transcript levels of GhMAPK increased transiently and rapidly, the mRNA accumulation increased markedly within $15 \mathrm{~min}$, and then decreased to the base level after $1 \mathrm{~h}$ (Fig. 5A). This response is much similar to the response of WIPK (wound inducible protein kinase) in tobacco (Zhang and Klessig, 1998). Both cold $\left(4^{\circ} \mathrm{C}\right)$ and salt stresses lead to an elevation of GhMAPK mRNA levels. The accumulation of the $G h M A P K$ transcript in leaves of cotton seedling was substantially induced by $4^{\circ} \mathrm{C}$ treatment during an 8 -h period (Fig. 5B). Under salt stress, the transcript of GhMAPK began to accumulate after $1 \mathrm{~h}$ and increased to a high level within $4 \mathrm{~h}$, then declined. But interestingly, another peak emerged at $8 \mathrm{~h}$ (Fig. 5C), this pattern was similar to that of BnMPK3 from oilseed (Yu et al., 2005), and this result may suggest an existence of a feedback adjustment in salt-stress signaling pathway.

Effect of signaling molecules on the transcription level of $\boldsymbol{G h M A P K}$. Studies have shown that wounding and pathogen 


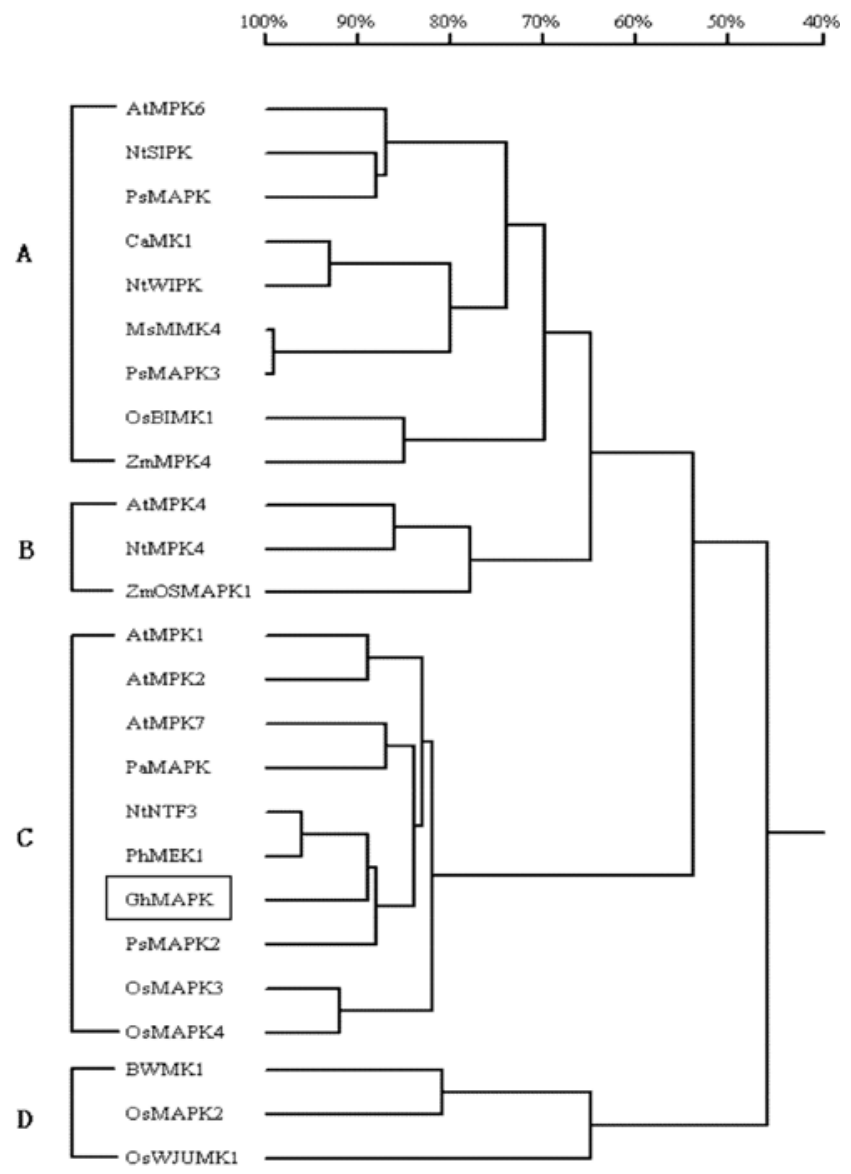

Fig. 2. Dendrogram of cotton GhMAPK with other MAPKs from plant species. The tree was generated using DNAMAN version 4.0 (Lynnon BioSoft company, USA). The protein sequences of the MAPKs used for construction of the tree are listed in the GenBank database under the following accession numbers: AtMPK6 (D21842) from Arabidopsis thaliana, NtSIPK (U94192) from Nicotiana tabacum, PsMAPK (X70703) from Pisum sativum, CaMK1 (AF247135) from Capsicum annuum, NtWIPK (D61377) from Nicotiana tabacum, MsMMK4 (X82270) from Medicago sativa, PsMAPK3 (AF153061) from Pisum sativum, OsBIMK1 (AF332873) from Oryza sativa, ZmMPK4 (AB016801) from zea mays, AtMPK4 (D21840) from Arabidopsis thaliana, NtMPK4 (AB212070) from Nicotiana tabacum, ZmOSMAPK1 (DQ422149) from zea mays, AtMPK1 (D14713) from Arabidopsis thaliana, AtMPK2 (D14714) from Arabidopsis thaliana, AtMPK7 (D21843) from Arabidopsis thaliana, PaMAPK (AF134730) from Prunus armeniaca, NtNTF3 (X69971) from Nicotiana tabacum, PhMEK1 (X83440) from Petunia $x$ hybrida, GhMAPK (DQ132852) from Gossypium hirsutum, PsMAPK2 (AF154329) from Pisum sativum, OsMAPK3 (AF216317) from Oryza sativa, OsMAPK4 (AJ251330) from Oryza sativa, BWMK1 (AF177392) from Oryza sativa, OsMAPK2 (AF194416) from Oryza sativa, OsWJUMK1 (AJ512643) from Oryza sativa.

response share a number of component in their signaling pathways (Cheong et al., 2002) and we hypothesize that wounding and pathogen response may be integrated by some

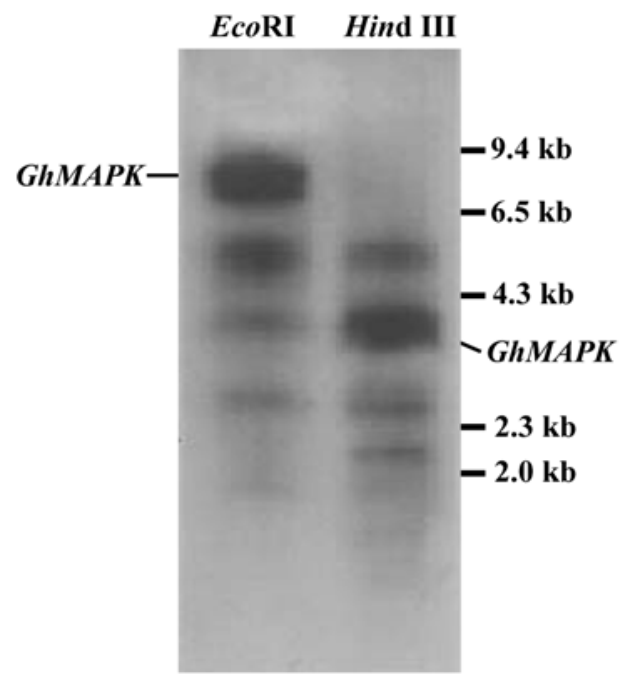

Fig. 3. Southern blot analysis of GhMAPK. Genomic DNA ( 30 $\mathrm{mg} /$ sample) from leaves was digested with EcoRI and Hind III respectively, separated on a $1.0 \%$ agarose gel, and hybridized with 3'-end divergent region of GhMAPK as probe. Molecular weight markers are shown on the right side of the figure. Note that EcoRI and Hind III have no restriction site within the probe sequence.

mechanisms that plants have developed. As we have found that $G h M A P K$ can be markedly induced by wounding, we further investigated the expression patterns of GhMAPK under treatments with $\mathrm{SA}$ and $\mathrm{H}_{2} \mathrm{O}_{2}$ respectively, which were two classic signal molecules in plant defense responses.

In plant, reactive oxygen species (ROS) can be formed as metabolic by-product under various abiotic stress conditions as well as pathogen attacks (Apel and Hirt, 2004). ROSinduced activation of MAPKs can be taken as evidence that ROS act upstream of MAPK pathways (Samuel et al., 2000). Among different ROS, only hydrogen peroxide $\left(\mathrm{H}_{2} \mathrm{O}_{2}\right)$ can cross plant membranes and can therefore directly function in cell-to-cell signaling, at the same time, it has been reported that $\mathrm{H}_{2} \mathrm{O}_{2}$ activated an MAPK cascade in Arabidopsis and soybean (Kovtun et al., 2000; Taylor et al., 2001). Thus we examined the expression of the GhMAPK gene in respond to $\mathrm{H}_{2} \mathrm{O}_{2}$ treatment, and the result was shown in Fig. 6A. Increase in accumulation of GhMAPK transcript was detected $1 \mathrm{~h}$ after treatment, reaching a maximum at $6 \mathrm{~h}$.

Many studies have demonstrated that Salicylic acid (SA) as an endogenous signal plays a critical role in the activation of several plant defense responses, including the synthesis of pathogenesis-related (PR) proteins (Ryals et al., 1996), the involvement in the establishment of localized hypersensitive reaction (HR), as well as systemic acquire resistance (SAR) (Halim et al., 2006). In this study, application of $10 \mathrm{mmol} / \mathrm{L}$ $\mathrm{SA}$ to the leaf resulted in accumulation of GhMAPK mRNA. Transcript levels of GhMAPK increased gradually, maximum levels was observed $6-8 \mathrm{~h}$ after SA treatment, and then declined (Fig. 6B). 


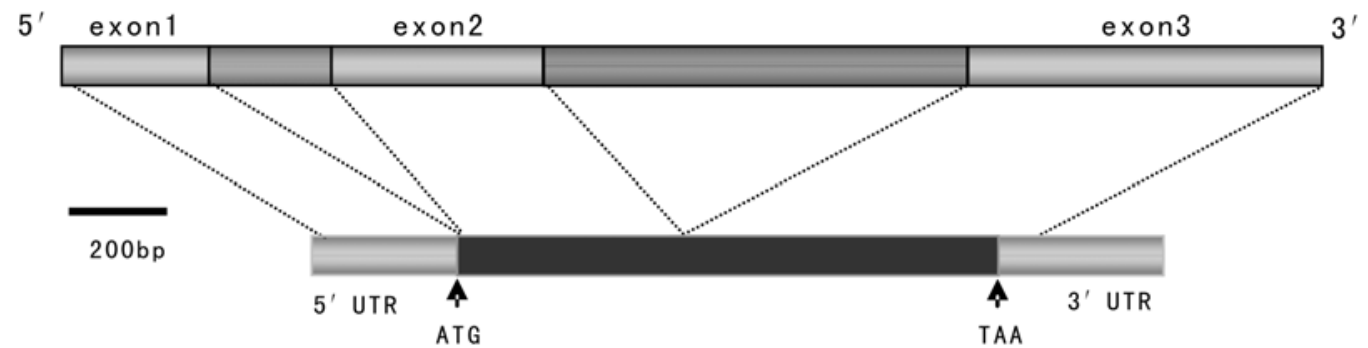

Fig. 4. Schematic representation of the GhMAPK genomic and mRNA structure. A genomic sequence with two introns (248 and $865 \mathrm{bp}$ each) and an mRNA sequence with marked coding region are shown.

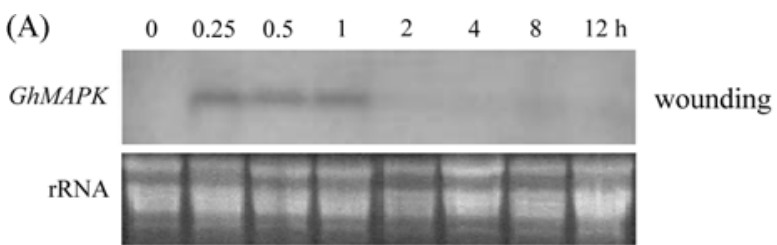

(B)
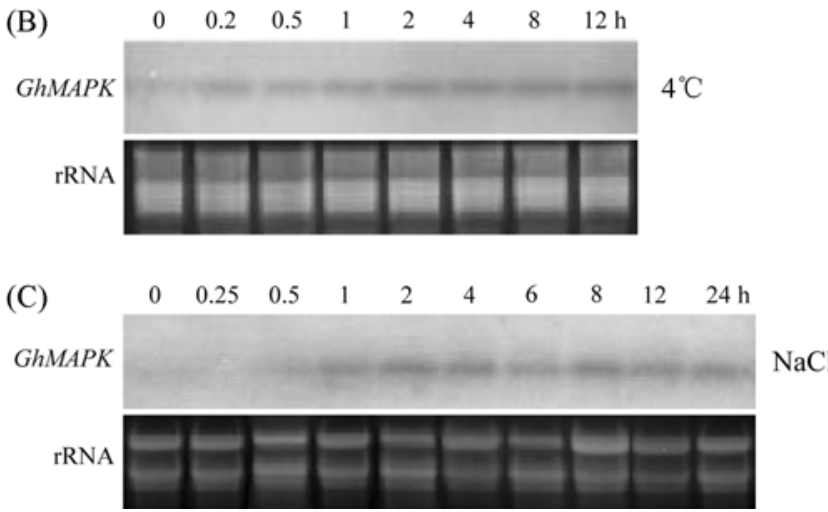

Fig. 5. Northern blot analysis of the induction of GhMAPK by wounding (A), low temperature $\left(4^{\circ} \mathrm{C}\right)(\mathrm{B}), 200 \mathrm{mM} \mathrm{NaCl}(\mathrm{C})$. Total RNA was isolated at indicated times after the treatments and was subjected to Northern blotting analysis using $\left[\alpha-{ }^{32} \mathrm{P}\right]$ labled GhMAPK cDNA as probe. The ethidium bromide stained ribosomal RNA (rRNA) is included as loading control.

Our results strongly suggest that the transcript of GhMAPK can be up-regulated by two signaling molecules, $\mathrm{H}_{2} \mathrm{O}_{2}$ and $\mathrm{SA}$, which can interact with MAPK cascade and play important role in plant defense response.

mRNA accumulation of GhMAPK under biotic stress. To gain more direct evidence on whether the GhMAPK is involved in pathogen attack response, we inoculate Fusarium oxysporum f. sp. vasinfectum that causes cotton wilt and possesses important application potential in plant antifungal genetic engineering in cotton seedlings. The Northern blotting analysis indicated that the GhMAPK expression level was upregulated apparently (Fig. 7).

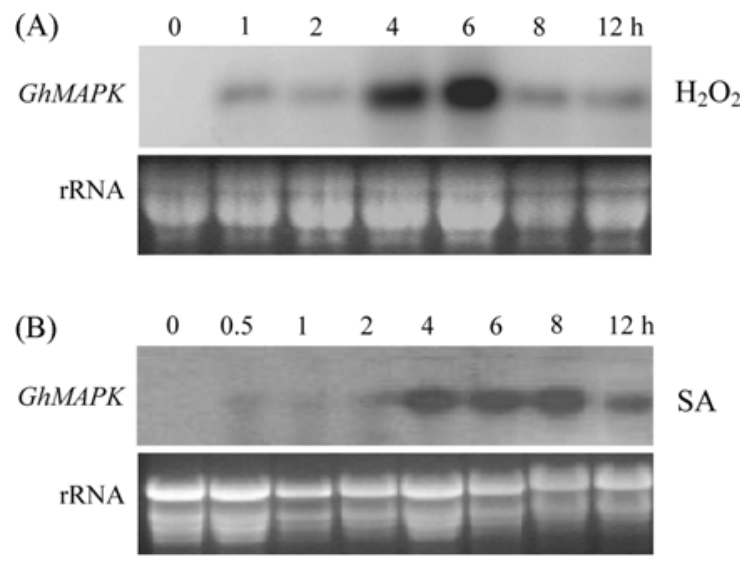

Fig. 6. Northern blot analysis of the induction of GhMAPK gene by $10 \mathrm{mM} \mathrm{H}_{2} \mathrm{O}_{2}$ (A), $10 \mathrm{mM}$ SA (B). Total RNA was isolated at indicated times after the treatments and was subjected to Northern blotting analysis using $\left[\alpha-{ }^{32} \mathrm{P}\right]$ labled GhMAPK cDNA as probe. The ethidium bromide stained ribosomal RNA (rRNA) is included as loading control.

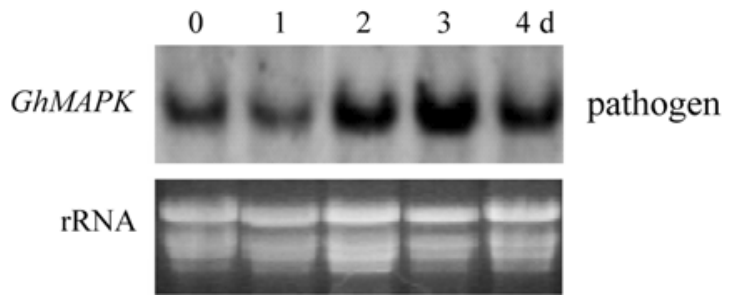

Fig. 7. Northern blot analysis of the induction of GhMAPK gene by pathogen infection. One-week-old cotton seedlings were inoculated with Fusarium oxysporum f. sp. Vasinfectum, days after inoculation are shown in the figure. $\left[\alpha-{ }^{32} \mathrm{P}\right]$ labled GhMAPK cDNA was used as probe. The ethidium bromide stained ribosomal RNA (rRNA) is included as loading control.

\section{Discussion}

The MAPK cascades play crucial roles in plant growth and development, as well as in biotic- and abiotic-stress responses, and a surprisingly large number of $M A P K$ genes from 
different species have been isolated and characterized in recent years, including at least 20 in genome of Arabdopsis (MAPK group, 2002), and 17 in rice (Reyna and Yang, 2006). Based on the predicted amino acid sequence homology and phosphorylation motif, plant MAPKs can be divided into at least four groups (A-D), and it has been assumed that MAPKs within one group have similar functions among plant species (MAPK group, 2002; Jonak et al., 1999). The information about the functions of MAPKs in group $\mathrm{C}$ is relatively rare and is just emerging recently. Two members of group C, NtNTF3 (Wilson et al., 1997) and PhMEK1 (DecroocqFerrant et al., 1995) are involved in pollen or ovule development. ATMPK1, was affected by salt-stress treatment (Mizoguchi et al., 1996). A big step has been made by the isolation of OsMAPK4 (also known as OsMSRMK3, OsMPK4), a group$\mathrm{C}$ MAPK which has been well characterized as how it relate to the plant defense response ( $\mathrm{Fu}$ et al., 2002; Agrawal et al., 2003). These evidences showed that the group-C MAPKs maybe also associated with biotic and abiotic stress responses, which further suggested that sequence-based phylogenetic clustering of MAPK orthologues among different species could not reliably predict their functions, and these must be established experimentally on a case-by-case basis (MAPK group, 2002; Nakagami et al., 2005).

In this study, we isolated the first $M A P K$ gene from cotton, namely $G h M A P K$, and the amino acid sequence comparison reveals that GhMAPK belongs to the group $\mathrm{C}$ of plant MAPK, characterized by the presence of the TEY activation motif in their T-loop and the 11 protein kinase (PK) subdomains. Furthermore, we analyzed the transcriptional patterns of $G h M A P K$ against a variety of stresses.

In plant, MAPKs become activated not only by posttranslational phosphorylation but also by transcriptional control, while in yeast and mammals, the MAPKs are activated solely by the first way (Widmann et al., 1999). In recent years, more and more studies have shown that transcriptional activation of plant MAPK genes was common. For instance, ATMPK3 in Arabidopsis (Mizoguchi et al., 1996) and MMK4 in alfalfa (Jonak et al., 1996) both show mRNA accumulation under drought and cold stresses. In rice, the expression of many MAPK genes, such as $B W M K 1$, $O s B I M K 1$ and $O s M A P K 5$, is also activated by various stresses (He et al., 1999; Song and Goodman, 2002; Xiong and Yang, 2003). Interestingly, though information is limited, we found that activation of group-C MAPKs showed mainly on transcriptional level. In our study, the expression pattern of the GhMAPK was analyzed by Northern blotting. The results showed that $G h M A P K$ could be markedly induced by wounding. Keeping in mind that among the wound-responsive genes identified in previous studies, a large fraction of them are known to be pathogen responsive genes or are postulated to play a role in pathogen resistance (Zhang and Klessig, 1998; He et al., 1999; Song and Goodman, 2002), we further found that $G h M A P K$ was activated in transcriptional level by both $\mathrm{SA}$ and $\mathrm{H}_{2} \mathrm{O}_{2}$ treatment, which play important roles in signaling defense responses. Thus, it is tempting to speculate that the GhMAPK is also involved in responses to pathogen infection. To gain more direct evidence, we examined its expression profiles following the inoculation of Fusarium oxysporum f. sp. Vasinfectum. The mRNA of GhMAPK was found to be induced within days after fungal infection. That was similar to another group-C member, OsMAPK4 (Reyna and Yang, 2006).

Since expression of GhMAPK was activated by wounding, cold, salt-stress and chemical inducers as well as in the incompatible interaction between cotton and Fusarium oxysporum f. sp. vasinfectum, it is a reasonable hypothesis that a putative GhMAPK-mediaed MAPK cascade is a common signaling event that is shared by various signaling pathways leading to activation of defense responses in cotton, just like the hypothesis that MAPKs act as a converging point for many different signals (Zhang and Klessig, 2001). However, the biochemical mechanism for activation of GhMAPK enzymatic activity in the defense response and whether induction of $G h M A P K$ gene expression is required for activation of its activity need to be studied further, and transgenic analysis may also helpful in addressing whether the GhMAPK is a positive or negative regulator of abiotic- and biotic- stress tolerance.

Acknowledgments This work was financially supported in part by the National Natural Science Foundation of China (No.30370928 and No.30571215). We also like to thank Zhiguo Ju (Chief Research Scientist of Liposcience International LLC, Chicago, USA) for critical reading of the manuscript.

\section{References}

Agrawal, G. K., Agrawal, S. K., Shibato, J., Iwahashi, H. and Rakwal, R. (2003) Novel rice MAPK kinase OsMSRMK3 and OsWJUMK1 involved in encountering diverse environmental stresses and developmental regulation. Biochem. Biophys. Res. Commun. 300, 775-783.

Agrawal, G. K., Rakwal, R. and Iwahashi, H. (2002) Isolation of novel rice (Oryza sativa L.) multiple stress responsive MAP kinase gene, OsMSRMK2, whose mRNA accumulates rapidly in response to environmental cues. Biochem. Biophys. Res. Commun. 294, 1009-1016.

Apel, K. and Hirt, H. (2004) Reactive oxygen species, metabolism, oxidative stress, and signal transduction. Annu Rev. Plant Biol. 55, 373-399.

Asai, T., Tena, G, Plotnikova, J., Willmann, M. R., Chiu, W. L., Gomez-Gomez, L., Boller, T., Ausubel, F. M. and Sheen, J. (2002) MAP kinase signaling cascade in Arabidopsis innate immunity. Nature 415, 977-983.

Baögre, L., Calderini, O., Binarova, P., Matlauch, M., Till, S., Kiegerl, S., Jonack, C., Pollaschek, C., Baker, P., Huskisson, NS., Hirt, H. and Heberle-Bors, E., (1999) A MAP kinase is activated late in mitosis and becomes localised to the plane of cell division. Plant Cell 11, 5-14.

Champin, A., Picaud, A., and Henry, Y. (2005) Reassessing the 
MAP3K and MAP4K relationships. Thends in plant Sci. 9, 123128.

Cheong, Y. H., Chang, H. S., Gupta, R., Wang, X., Zhu, T. and Luan, S., (2002) Transcriptional Profiling Reveals Novel Interactions between Wounding, Pathogen, Abiotic Stress, and Hormonal Responses in Arabidopsis. Plant Physiol. 129, 661-677.

Cheong, Y. H., Moon, B. C., Kim, J. K., Kim, C. Y., Kim, M. C., Kim, I. H., Park, C. Y., Kim, J. C., Park, B. O., Koo, S. C., Yoon, H. W., Chung, W. S., Lim, C. O., Lee, S. Y. and Cho, M. J. (2003) BWMK1, a rice mitogen-activated protein kinase, locates in the nucleus and mediates pathogenesis-related gene expression by activation of a transcription factor. Plant Physiol. 132, 1961-1972.

Cobb, M. H. and Goldsmith, E. J. (1995) How MAP kinase are regulated. J. Biol. Chem. 270, 14843-14846.

Decroocq-Ferrant, V., Decroocq, S., van Went, J., Schmidt, E. and Kreis, M. (1995) A homologue of the MAP/ERK family of protein kinase genes is expressed in vegetative and in female reproductive organs of Petunia hybrida. Plant Mol. Biol. 27, 339350.

Dowd, C, Wilson, I. W. and McFadden, H. (2004) Gene expression profile changes in cotton root and hypocotyl tissues in response to infection with Fusarium oxysporum f. sp. vasinfectum. Mol Plant Microbe Interact. 17, 654-667.

Fu, S. F., Chou, W. C., Huang, D. D. and Huang, H. J. (2002) Transcriptional regulation of a rice mitogen-activated protein kinase gene, OsMAPK4, in response to environmental stress. Plant Cell Physiol. 43, 958-963.

He, C., Fong, S. H. T., Yang, D. and Wang, G. L. (1999) BWMK1, a novel MAP kinase induced by fungal infection and mechanical wounding in rice. Mol. Plant Microbe Interact. 12, 1064-1073.

Hirt, H. (1997) Multiple roles of MAP kinases in plant signal transduction. Trends Plant Sci. 2, 11-15.

Halim, V. A., Vess, A., Scheel, D. and Rosahl, S. (2006) The role of salicylic acid and jasmonic acid in pathogen defence. Plant Biol(stuttq). 8(3), 307-313.

Jeong, M. J., Lee, S. K., Kim, B. J., Kwon, T. R., Cho W. S., Park, Y. T., Lee, J. O., Kwon, H. B., Byun, M. O. and Park, S. C. (2006) A rice (Oryza stativa L.) MAP kinase gene, OsMAPK44, is involved in response to abiotic stresses. Plant Cell, Tissue and Organ Culture 85, 151-160.

Jonak, C., Kiegerl, S., Ligterink, W., Baker, P. J., Huskisson, N. S. and Hirt, H. (1996) Stress signaling in plants, A mitogenactivated protein kinase pathway is activated by cold and drought. Proc. Natl. Acad. Sci. USA 93, 11274-11279.

Jonak, C., Ligterink, W. and Hirt, H. (1999) MAP kinase in plant signal transduction. Cell. Mol. Life Sci. 55, 204-213.

Jonak, C., Okresz, L., Boger, H. and Hirt, H. (2002) Complexity cross talk and integration of plant MAP kinase signaling. Curr. Opin. Plant Biol. 5, 415-424.

Jonak, C., Nakagami, H. and Hirt, H. (2004) Heavy metal stress. Activation of destinct mitogen-activated protein kinase pathways by copper and cadmium. Plant Physiol., 136, 3276-3283.

Kovtun, Y., Chiu, W. L., Tena, G and Sheen, J. (2000) Functional analysis of oxidative stress-activated mitogen-activated protein kinase cascade in plants. Proc. Natl. Acad. Sci. USA 97, 29402945.

MAPK Group. (2002) Mitogen-activated protein kinase cascades in plants: A new nomenclature. Trends Plant Sci. 7, 301-308.

Mizoguchi, T., Irie, K., Hirayama, T., Hayashida, N., Yamaguchi-
Shinozaki, K., Matsumoto, K. and Shinozaki, K. (1996) A gene encoding a mitogen-activated protein kinase kinase kinase is induced simultaneously with genes for a mitogen-activated protein kinase and S6 ribosomal protein kinase by touch, cold, and water stress in Arabidopsis thaliana. Proc. Natl. Acad. Sci. USA 93, 765-769.

Nakagami, H., Pitzschke, A. and Hirt, H (2005) Emerging MAP kinase pathways in plant stress signalling. Trends Plant Sci. 10, 339-346.

Reyna, N. S. and Yang, Y. N. (2006) Molecular analysis of the rice MAP kinase gene family in relation to Magnaporthe grisea infection. Mol. Plant Microbe Interact. 19, 530-540.

Ouaked. F., Rozhon, W., Lecourieux, D. and Hirt, H. (2003) A MAPK pathway mediates ethylene signaling in plants. EMBO J. 22, 1282-1288.

Ryals, J.A., Neuenschwander, U. H., Willits, M. G., Molina, A., Steiner, H.-Y. and Hunt, M. D. (1996) systemic acquired resistance. Plant cell 8, 1809-1819.

Sambrook, J., Fritsch, E. F. and Maniatis, T. (1989) Molecular Cloning, A Laboratory Manual, 2nd ed., Cold Spring Harbor Laboratory Press, New York, USA.

Samuel, M. A., Miles, G. P. and Ellis, B. E. (2000) Ozone treatment rapidly activates MAP kinase signalling in plants. Plant $J$. 22, 367-376.

Seo, S., Sano, H. and Ohashi, Y. (1999) Jasmonate-based wound signal transduction requires activation of WIPK, a tobacco mitogen-activated protein kinase. Plant Cell 11, 289-298.

Song, F. and Goodman, R. M. (2002) OsBIMK1, a rice MAP kinase gene involved in disease resistance responses. Planta 215, 997-1005.

Stone, J. M. and Walker, J. C. (1995). Plant protein kinase families and signal transduction. Plant Physiol. 108, 451-457.

Tanoue, T., Adachi. M., Moriguchi, T. and Nishida, E. (2000) A conserved docking motif in MAP kinases common to substrates, activators and regulators. Nat. Cell Biol. 2, 110-116.

Taylor, A. T., Kim, J. and Low, P. S. (2001) Involvement of mitogen-activated protein kinase activation in the signaltransduction pathways of the soya bean oxidative burst. Biochem. J. 355, 795-803.

Trewavas, A. and Gilroy, S. (1991) Signal transduction in plant cells. Trends Genet. 7, 356-361.

Wilson, V., Voronin, A., Touraev, O., Vincente, E. and Heberle-Bors. (1997) A developmentally regulated MAP kinase activated by hydration in tobacco pollen. Plant Cell 9, 2093-2100.

Widmann, C., Gibson, S., Jarpe, M. B. and Johnson, G L. (1999) Mitogen-activated protein kinase, conservation of a three-kinase module from yeast to human. Physiol. Rev. 79, 143-180.

Xiong, L. and Yang, Y. (2003) Disease resistance and abiotic stress tolerance in rice are inversely modulated by an abscisic acidinducible mitogen-activated protein kinase. Plant Cell 15, 745759.

Yu, S. W., Zhang, L. D., Zuo, K. J., Tang, D. Q. and Tang, K. X. (2005) Isolation and characterization of an oilseed rape MAP kinase BnMPK3 involved in diverse environmental stresses. Plant Sci. 169, 413-421.

Zhang, S. and Klessig, D. F. (1998) The tobacco woundingactivated mitogen-activated protein kinase is encoded by SIPK. Proc. Natl. Acad. Sci. USA 95, 7225-7230.

Zhang, S. and Klessig, D. F. (2001) MAPK cascades in plant defense signaling. Trends Plant Sci. 6, 520-527. 